\title{
Review: bisphosphonates reduce fractures, radiotherapy, and hypercalcaemia and increase time to a first skeletal related event
}

Ross JR, Saunders Y, Edmonds PM, et al. Systematic review of role of bisphosphonates on skeletal morbidity in metastatic cancer. BMJ 2003;327:469-72.

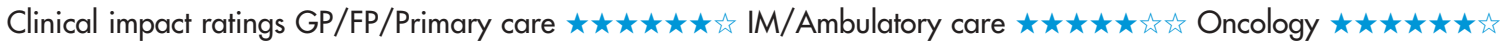

In cancer patients with bone metastases, do bisphosphonates reduce skeletal morbidity?

\section{METHODS}

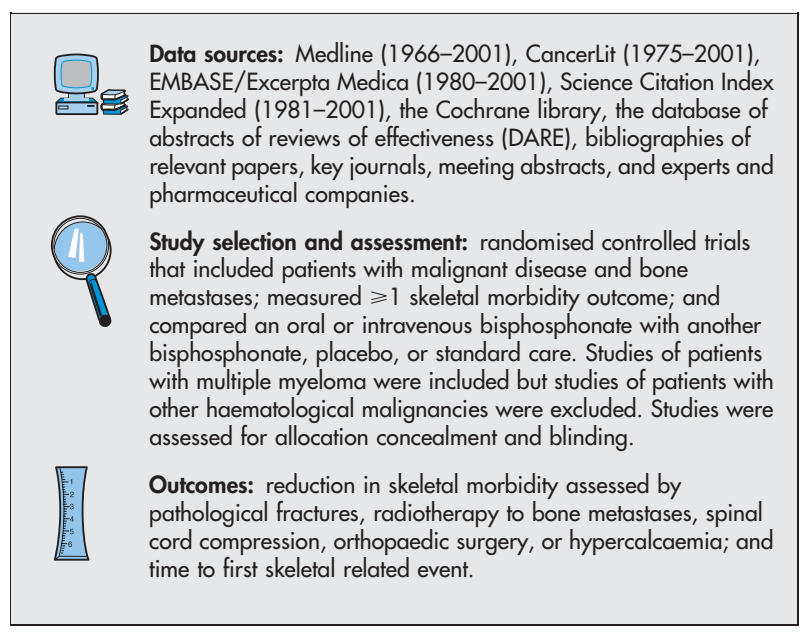

\section{MAIN RESULTS}

30 studies met the selection criteria. 18 studies were eligible for examination by meta analysis, 3 of which had data that could be used only for time to first skeletal related event. Of the remaining 15

For correspondence: Dr J R Ross, Royal Marsden Hospital, London, UK joy.ross@talk21.com

Source of funding: NHS Health and Technology Assessment Programme.

Bisphosphonates (Bis) $v$ placebo or control in metastatic bone disease*

\begin{tabular}{|c|c|c|c|}
\hline $\begin{array}{l}\text { Outcomes at } \\
\geqslant 6 \text { months }\end{array}$ & $\begin{array}{l}\text { Weighted event } \\
\text { rates } \\
\text { Bis } v \text { placebo or } \\
\text { control }\end{array}$ & RRR (95\% Cl) & NNT (CI) \\
\hline $\begin{array}{l}\text { Vertebral } \\
\text { fractures }\end{array}$ & $18 \% \vee 22 \%$ & $23 \%(10$ to 35$)$ & 22 (14 to 44$)$ \\
\hline $\begin{array}{l}\text { Non-vertebral } \\
\text { fractures }\end{array}$ & $16 \%$ v $22 \%$ & $28 \%$ (15 to 38 ) & 18 (12 to 38 ) \\
\hline $\begin{array}{l}\text { Combined } \\
\text { fractures }\end{array}$ & $27 \%$ v $34 \%$ & $24 \%$ (14 to 32 ) & 14 (10 to 24 ) \\
\hline $\begin{array}{l}\text { Radiotherapy } \\
\text { Hypercalcaemia }\end{array}$ & $\begin{array}{r}28 \% \vee 36 \% \\
8 \% \vee 11 \%\end{array}$ & $\begin{array}{l}23 \%(15 \text { to } 31) \\
40 \%(15 \text { to } 58)\end{array}$ & $\begin{array}{l}12(8 \text { to } 22) \\
30(19 \text { to } 74)\end{array}$ \\
\hline $\begin{array}{l}\text { Orthopaedic } \\
\text { surgery }\end{array}$ & $6 \% \vee 7 \%$ & $29 \%(-4$ to 41$)$ & Not significant \\
\hline $\begin{array}{l}\text { Spinal cord } \\
\text { compression }\end{array}$ & $3 \% \vee 4 \%$ & $22 \%(-16$ to 48$)$ & Not significant \\
\hline
\end{tabular}

*Abbreviations defined in glossary; RRR, NNT, and $\mathrm{Cl}$ calculated from data in article using a random effects model. Studies ranged in duration from 6 months to $>2$ years. studies, 3 compared 2 bisphosphonates and 12 compared a bisphosphonate ( 5 studies of clodronate, 4 of pamidronate, 2 of zoledronic acid, and 1 of etidronate) with placebo or control. Compared with placebo, bisphosphonates reduced the risk of vertebral fractures, non-vertebral fractures, combined fractures, radiotherapy, and hypercalcaemia but not orthopaedic surgery or spinal cord compression (table). 10 studies recorded time to first skeletal related event for patients treated with bisphosphonates compared with control, 8 of which showed increased time to first skeletal related event for patients who received intravenous bisphosphonates.

\section{CONCLUSION}

In cancer patients with bone metastases, bisphosphonates reduce fractures, radiotherapy, and hypercalcaemia and increase time to a first skeletal related event.

Commentary

$M$ etastatic bone disease is a major cause of distress in patients with cancer. Each year in the UK, $>25000$ people die with bone metastases. These patients are mainly concerned with control of pain and being able to live as normal a life as possible. "Skeletal events" was the primary endpoint used in the review by Ross et al. This is a nonspecific but popular endpoint mainly because events can be enumerated easily. More important factors such as quality of life are harder to measure and less often considered. For example, in a different review of the role of bisphosphonates, Wong and Wiffen could identify only 2 eligible trials that used pain as an outcome measure. ${ }^{1}$ We also need quantitative information on the harms associated with bisphosphonate treatment. Ross et al used data provided by 1 manufacturer (Novartis) in advance of publication (ie, "Unpublished C," a large study favouring the intervention and published in October 2002). However, another study (sponsored by Roche) that was not included in this meta-analysis was also published in May 2002; this study showed no benefit from bisphosphonates. ${ }^{2}$ This epitomises the difficulty of obtaining stable conclusions from meta-analyses when the number of studies is small, some are still being prepared for publication, and the publication times of primary studies and their derivative meta-analyses are protracted and overlapping.

In summary, the analysis and interpretation of trials and overviews concerning the use of bisphosphonates remain controversial, particularly given the paucity of data concerning the most important endpoints, pain control and quality of life. The review by Ross et al highlights the difficulties but leaves the real questions tantalisingly open. Still, no unequivocal case for the routine use of bisphosphonates in patients with metastatic cancer exists.

Alastair J Munro Ninewells Hospital, University of Dundee Dundee, UK

1 Wong R, Wiffen PJ. Cochrane Database Syst Rev 2002;(2):CD002068.

2 Menssen HD, Sakalova A, Fontana A, et al. J Clin Oncol 2002;20:2353-9. 